\title{
Induction of cytotoxic T lymphocytes primed with Tumor RNA-loaded Dendritic Cells in esophageal squamous cell carcinoma: preliminary step for DC vaccine design
}

\author{
Mehran Gholamin', Omeed Moaven', Moein Farshchian', Mahmoud Mahmoudi2, Mojtaba Sankian3, \\ Bahram Memar ${ }^{4}$, Mohammad Naser Forghani5, Reza Malekzadeh5, Mohammad Taghi Rajabi-Mashhadi6 and \\ Mohammad Reza Abbaszadegan*1
}

\begin{abstract}
Background: Dendritic Cells (DC) are potent antigen presenting cells with the ability to prime naïve T cells and convert them to cytotoxic T-lymphocytes (CTL). We evaluated the capability of autologous DCs transfected with total tumor and normal RNA to induce cytotoxic CTL as the preliminary step to design a DC-based vaccine in the esophageal squamous cell carcinoma (ESCC).

Methods: Monocytes-derived DCs were electroporated with either total tumor RNA or normal RNA. T cells were then primed with tumor RNA transfected DCs and lytic effects of the generated CTL were measured with Cytotoxicity assay and IFN- $\gamma$ Release Elispot assay.

Results: Cytotoxicity was induced against DCs loaded with tumoral RNA (\%24.8 \pm 5.2 SEM) while in normal RNAloaded DCs, it was minimal (\%6.1 \pm 2.4 SEM) and significantly lower $(p<0.05)$. INF- $\gamma$ secretion was more than 2 -folds higher in tumoral RNA-loaded DCs when compared with normal RNA-loaded DCs $(p<0.05)$.

Conclusion: Electroporating DCs with tumor RNA generated tumor antigen presenting cells which in turn enhanced cytotoxic effects of the T cells against ESCC. This may be a useful autologous ex vivo screening tool for confirming the lytic effects of primed T cells on tumors and evaluate probable further adverse effects on noncancerous tissues. These data provide crucial preliminary information to establish a total tumor RNA-pulsed DC vaccine therapy of ESCC.
\end{abstract}

\section{Background}

Gastrointestinal cancers are the most frequent cancer malignancy in the Iranian population with substantial numbers of the patients reported from northern and northeastern Iran. Esophageal squamous cell carcinoma (ESCC) is the fifth leading cause of cancer-related deaths in Iran [1]. Most cases of ESCC in Iran as well as many other countries are diagnosed in advanced stages [2]. Surgical treatment and adjuvant therapeutic modalities such as chemo- and radiotherapy have only a minimal effect

\footnotetext{
* Correspondence: abbaszadeganmr@mums.ac.ir

${ }^{1}$ Division of Human Genetics, Immunology Research Center, Avicenna Research Institute, Mashhad University of Medical Sciences (MUMS), Mashhad, Iran

Full list of author information is available at the end of the article
}

on patient outcome and the overall 5 -years survival rate is less than $25 \%$.

Immune system plays an important role in counterbalancing against the malignant transformation and escape from immunologic surveillance and the subsequent immune privilege of tumor may account for the development of some cancers including ESCC [3]. On the other hand, the suggested correlation between the infiltration of $\mathrm{T}$ cells in the tumor environment and good prognosis demonstrated in several tumors represents a naturally occurring adaptive immunity in cancer patients [4]. Immunotherapeutic strategies are designed and optimized based on a better understanding of different escape mechanisms. Nonfunctional presentation of tumoral antigen and further suppression of an effective 
immune response is one of the most important mechanisms of immune evasion which has been targeted in designing a number of immunotherapeutic modalities.

Dendritic cells (DC) are professional antigen capturing cells which initiate primary and further secondary immune responses in vivo. Their unique functions are mediated by priming the naïve $T$ cells and cross-presenting various antigens. Maturation is an important characteristic of DCs during which immature DCs, as phagocytic cells capture foreign antigens at the site of injury and become mature cells along the process of presenting the antigen peptides on MHC class I and II molecules [5]. Mature DCs will then migrate to local lymph nodes to present antigens to naïve $\mathrm{T}$ cells and convert them into effector cells of the immune system against non-self antigens [6]. Taking advantage of this in vivo model, incubation of DCs with tumor specific molecules such as proteins, peptides, or lysates, or transfecting them with nucleic acids encoding tumor specific antigens is the basic concept of designing DC-based cancer immunotherapy [7].

Electroporation is assumed as the most efficient method for delivering the genetic materials into the cells [8]. In this procedure, a mixture of cells and mRNA are pulsed at a specific voltage for a short period of time. Resulting is a small pore on the cell membrane which makes it possible to pass mRNA into the cells [9]. Gilboa et al pulsed DCs with tumor antigen-encoding mRNA and reported an effective therapeutic tumor vaccination when it was administered in a murine model for the first time [10]. Although various studies have tried to find a specific tumor marker for ESCC, an appropriate marker has yet to be found for the purpose of immunotherapy. Therefore, in this study we loaded DCs with total mRNA to transfer the genetic material. T cell response was evaluated after priming with DCs transfected with tumoral mRNA from ESCC patients as a preliminary step to establish a DC vaccine for ESCC.

\section{Methods}

\section{Sample collection and RNA isolation}

Four histologically-approved ESCC patients were included in the study prior to any therapeutic interventions. After obtaining informed consents, approximately $50 \mathrm{ml}$ of blood was collected in heparinized vials for extraction of peripheral blood mononuclear cells (PBMCs). Tumoral tissue was microdissected and stored in RNAlater (Qiagen, Hilden, Germany) until RNA extraction. Corresponding normal tissue from the affected esophagus was obtained using the same protocol. Total RNA was extracted by RNeasy kit (Qiagen, Hilden, Germany). RNA integrity was confirmed by electrophoresis on agarose gel and the concentration and purity was checked by spectrophotometry at $260 \mathrm{~nm}$ and $280 \mathrm{~nm}$. The study was approved by the Research Ethics Committee of Mashhad University of Medical Sciences.

\section{Generation of dendritic cells}

Peripheral blood mononuclear cells were obtained from $50 \mathrm{ml}$ of heparinized whole blood via Ficoll-Hypaque (Biosera Inc., East Sussex, United Kingdom). The generation of DCs was performed on CD14+ cells isolated by the EasySep Human Monocyte Enrichment Kit without CD16 Depletion (Stemcell Technologies, Vancouver, Canada). Cells were seeded for 5 days into six-well plates in RPMI1640 supplemented by $10 \%$ heat-inactivated FBS, penicillin $(100 \mathrm{U} / \mathrm{ml})$, streptomycin $(100 \mathrm{mg} / \mathrm{ml})$, L-glutamine $(2 \mathrm{mM})$, sodium pyruvate, $2 \mathrm{ME}$ (2-Mercaptoethanol) (50 mM), human Granulocyte Monocyte-Colony Stimulating Factor (GM-CSF) 800 IU (R\&D System Inc., Minneapolis, MN, USA) and IL-4 500 IU (R\&D, USA). GM-CSF and IL-4 were again added on the third day. The production of immature DCs was detected by specific $C D$ markers using BD FACSCalibur (BD Biosciences, CA, USA). Cells were electroporated with tumor or normal mRNA on the sixth day, followed by the maturation of the cultured DCs with TNF- $\alpha(50 \mathrm{ng} / \mathrm{ml}) 4$ hours after electroporation. Electroporated mature cells were analyzed for transfection using flow cytometry after 24-48 hours.

\section{FACS (Fluorescence-Activated Cell Sorting) analysis of immature DC}

Immunofluorescence staining of monocyte-derived DC with differentiation and activation markers was performed for the phenotypic analysis of DCs. Anti-HLA DR, CD1a, CD80, CD86, CD83, FITC-conjugated (Fluorescein Isothiocyanate), and CD14 PE-conjugated (Phycoerytherin) mouse monoclonal antibodies (IQ Company, Netherlands) were used for the FACS analysis. Appropriate mouse PE/FITC isotype was used as negative control.

\section{RNA electroporation}

Prior to electroporation on day 6, immature DCs were washed twice with the Opti-MEM medium (GibcoBRL, Eggenstein, Germany) and resuspended to a final concentration of $10 \times 10^{6}$ cells $/ \mathrm{ml}$. Subsequently, $100 \mu \mathrm{l}$ of the cell suspension was initially mixed with $2.5 \mu \mathrm{g}$ of Enhanced Green Fluorescent Protein (EGFP) mRNA per $10^{6}$ cells to confirm the transfection procedure. After confirming the transfection procedure, DCs were transfected with $1.5 \mu \mathrm{g}$ of tumoral mRNA per $10^{6}$ cells or 1.5 $\mu \mathrm{g}$ of corresponding normal mRNA per $10^{6}$ cells. Transfection was performed using a BTX ECM830 squarewave electroporator with a single $500 \mathrm{~V} / 300 \mu$ s pulse (Genetronics, San Diego, CA, USA). 
After pulsing, all the cells were gently and immediately removed from the cuvette and poured into 6 well plates, in which the containing media was pre-warmed at $37^{\circ} \mathrm{C}$. For negative control of electroporation reaction, mock DCs were electroporated under the same conditions but without the addition of mRNA.

\section{Generation of in vitro-transcribed EGFP mRNA}

In order to confirm the gene transfer efficiency by the electroporation method, in vitro-transcribed (IVT) EGFP mRNA was applied as a reporter gene. pGEM4Z/GFP/ A64 plasmid containing the poly(A) template (kindly provided by Dr. E. Gilboa, University of Miami, FA, USA) was utilized for in vitro transcription of EGFP mRNA. This plasmid was transformed into E. coli Top10F and purified with a QIAprep Spin Miniprep Kit (Qiagen, Hilden, Germany). Following vector linearization by the restriction enzyme SpeI and purification, DNA template was used for in vitro transcription under the control of a T7 promoter with the T7 RNA polymerase. In vitro capped RNA was synthesized by the Message MACHINE kit (Ambion, Austin, TX, USA) according to the manufacturer's instructions. The concentration and purity of amplified EGFP RNA was evaluated by spectrometric analysis of absorbance at 260 (A260) and $280 \mathrm{~nm}$ (A280) and by $2 \%$ agarose/EtBr gel electrophoresis. The DCs electroporated with IVT EGFP mRNA were directly checked by fluorescent microscope and underwent FACS analysis to evaluate the efficiency of transfection which is represented by the percentage of transfected cells in a live population. The introduction efficacy is calculated by multiplying the percentage of viable cells by the transfection efficiency[11].

\section{Induction of tumor-specific CTL using DCs transfected with tumor RNA}

For CTL generation, the T-cell-enriched non-adherent fraction of PBMCs was obtained after the DC plastic adherence step was performed. T-Cells were suspended in RPMI1640 with 10\% fetal calf serum, 25 mM Hepes, Lglutamine, and antibiotics. Of the T-cell-enriched PBMCs, $2 \times 10^{6}$ cells were combined with $2 \times 10^{5}$ transfected matured DCs and $10 \mathrm{ng} / \mathrm{ml} \mathrm{IL-7} \mathrm{in} \mathrm{a} \mathrm{total} \mathrm{volume}$ of $2 \mathrm{ml}$, in the wells of a 24-well tissue culture plate and cultured at $37^{\circ} \mathrm{C}$ in $5 \% \mathrm{CO}_{2}$ for 8 days. IL-2 was added to the culture in the third day at a concentration of $20 \mathrm{IU} /$ $\mathrm{ml}$. After 8 days, the effectors were harvested, washed, counted, and re-stimulated with newly transfected DCs. Adding IL- 2 and IL-7 with the same concentrations to the culture, the cells were incubated for another 8 days to successfully induce tumor specific CTL.

\section{Cytotoxicity test}

To determine cytotoxicity, the calcein-AM cytotoxicity assay was performed. Prior to the cytotoxicity assay, target cells were re-suspended in RPMI-1640 complete medium at a final concentration of $10^{6} \mathrm{cells} / \mathrm{ml}$ and incubated with $10 \mu \mathrm{M}$ calcein-AM (Invitrogen inc., Grand Island, NY, USA) for $30 \mathrm{~min}$ at $37^{\circ} \mathrm{C}$ with occasional shaking, treated with $50 \mu \mathrm{g} / \mathrm{ml}$ of mitomycin $C$ for $30 \mathrm{~min}$, and washed three times with RPMI-1640 medium. Effectors and calcein-labeled targets were co-cultured in $\mathrm{U}$ bottom 96-well plates in triplicates for $4 \mathrm{~h}$ at $37^{\circ} \mathrm{C}$ in a total volume of $200 \mu \mathrm{l}$ with various effector:target (E:T) ratios i.e. 1:1, 3:1 and 9:1. Supernatant samples were measured using a fluorescence spectrophotometer (FP-6200, Jasco, Japan; exciting filter: $485 \pm 9 \mathrm{~nm}$; band-pass filter: $530 \pm 9 \mathrm{~nm})$. Data were expressed as arbitrary fluorescent units (AFU). Percent cytotoxicity of the assay was calculated by the following formula: [(test release - spontaneous release $) /($ maximum release - spontaneous release $)] \times$ 100. The maximum release and spontaneous release represent calcein release from the targets in the medium, with and without $2 \%$ Triton X-100, respectively.

\section{IFN- $\gamma$ release Elispot assay}

The IFN- $\gamma$ release Elispot assay was performed by an Elispot kit (U-CyTech biosciences, Utrecht, Netherlands) according to the manufacturer's instructions. Briefly, 96well plates with transparent membranes were coated with $50 \mu \mathrm{L}$ primary anti-IFN- $\gamma$ antibodies and incubated at $4^{\circ} \mathrm{C}$ for at least $18 \mathrm{~h}$. After washing the plates with the washing buffer five times, individual wells were blocked for nonspecific binding with $200 \mu \mathrm{L}$ RPMI containing $10 \% \mathrm{FBS}$ at $37^{\circ} \mathrm{C}$ for $1 \mathrm{~h}$. After removal of the blocking solution, $4 \times 10^{4}$ responder $\mathrm{T}$ cells and $2 \times 10^{3}$ mitomycin-treated stimulator cells were added in a total volume of $200 \mu \mathrm{L}$ RPMI medium containing 10\% FBS. Stimulator cells included DCs transfected with tumoral or normal mRNA and also mock DCs. Each experimental condition was plated in triplicates and incubated at $37^{\circ} \mathrm{C}$ in $5 \% \mathrm{CO}_{2}$ for $24 \mathrm{~h}$. Cultures were removed and the plates were washed ten times with the washing buffer. One hundred microliters of properly diluted biotinylated detection anti-IFN- $\gamma$ antibody was added to each well and incubated overnight at $4^{\circ} \mathrm{C}$. The plates were washed with the washing buffer five times and $50 \mu \mathrm{l}$ of labeled anti-biotin antibody was added to each well and incubated at $37^{\circ} \mathrm{C}$ in the dark for $1 \mathrm{~h}$. Washing was repeated five times and activator solutions were added to detect the sites of cytokine secretion by revealing the black spots. The plates were developed in the dark for $30 \mathrm{~min}$. The reactions were stopped by rinsing with tap water and spots were imaged and counted at the final step. 


\section{Statistical analysis}

Results were expressed as the mean \pm SD. Statistical analysis of cytotoxicity and Elispot tests were conducted by unpaired Student's $t$-test and paired Student $t$-test using SPSS software (version 16). A value of $\mathrm{p}<0.05$ was considered statistically significant.

\section{Results}

After preliminary optimization and confirming efficient gene transfer in one patient, a total of 3 patients were enrolled in the study. All the patients were histologically diagnosed as esophageal squamous cell carcinoma. Clinicopathological features of the patients are demonstrated in Table 1.

\section{FACS analysis of monocyte-derived DCs}

Immuno-phenotyping of the DCs was analyzed five days after monocytes were cultured and required cytokines were added. Specific CD markers including CD1a, CD14, CD80, CD86, CD83, and HLA-DR were detected to confirm the generation of immature DCs. CD14 was decreased to less than $1 \%$ and CD1a was increased to the average of approximately 95\%, representing transformation of monocytes into DCs. After 2 days, FACS analysis was performed to detect specific CD markers of matured DCs. CD83 was increased to an average of $58.9 \%$ confirming the maturation process. Results of the FACS analysis are shown in Table 2.

\section{Electroporation efficacy represented by GFP mRNA transfection into DC}

In order to establish the optimized gene delivery into monocyte-derived DCs, the transfection efficacy of in vitro transcribed GFP mRNA into DCs was first confirmed. Successful GFP expression, as a reporter gene, was assessed by fluorescent microscopy and FACS analyses. The average viability percentage of the transfected cell population was $94.5 \%$ as compared to $97.9 \%$ in mock cells and the average transfection efficiency was $87.8 \%$. The flow cytometry results of patient 1 are presented in Figure 1. The kinetic of GFP expression was analyzed afterwards and an approximately 30\% expression was detected $96 \mathrm{~h}$ after electroporation.

\section{Cytotoxicity results}

Cytotoxicity of primed lymphocytes with tumoral mRNA-loaded DCs in ESCC patients were assessed by measuring the cytotoxicity of CTLs against DC targets loaded with tumoral RNA, or normal RNA, or mock DC as negative control. Cytotoxicity percentage against DCs loaded with tumoral RNA ranged from 17.5 to 35.0. In all the patients, significant differences were observed between cytotoxicity against DCs loaded with tumoral RNA and mock DCs $(\mathrm{p}<0.05)$. Cytotoxicity against DCs loaded with tumoral RNA was significantly higher than the corresponding value for DCs loaded with normal RNA for each patient separately and when the average of the two groups were compared with paired $t$-test $(24.8 \pm$ 5.2 SEM and 6.1 \pm 2.4 SEM, p < 0.05). The Cytotoxicity results of the ESCC patients are shown in Figure 2.

\section{Elispot results}

Elispot assay was performed to reconfirm the significant differences between tumoral and normal mRNA-loaded DCs observed in the results of cytotoxicity assay. Specific $T$ cell activation and INF- $\gamma$ secretion was more than 2folds higher in tumoral RNA-loaded DCs when compared to normal RNA-loaded DCs in patients 3 and 4 ( $\mathrm{p}<$ 0.05 ). For patient 2, Elispot assay was not performed due to insufficient amount of DCs (less blood was possible to obtain from the patient) and only cytotoxicity test was performed. The results of the assay are shown in Figure 3.

\section{Discussion}

Due to its asymptomatic nature, ESCC is often diagnosed in its advanced stages where the common therapeutic modalities are not very effective and the 5-year survival rates do not exceed $25 \%$. Therefore, approaches to novel therapeutic modalities seem to be an essential step to improve the survival rate of ESCC patients. We have previously shown that immune escape is a frequent event in the Iranian ESCC patients. This suggests that immunotherapy can be a potentially effective tool to reverse

Table 1: Clinicopathological characteristics of patients.

\begin{tabular}{|c|c|c|c|c|c|}
\hline Patient & Age & Sex & Tumor Location & Tumor Grade & TNM Classification \\
\hline Patient 1 & 65 & Male & Middle & M.D. & T3NOMO \\
\hline Patient 2 & 51 & Female & Middle & M.D. & T3NOMO \\
\hline Patient 3 & 79 & Male & Middle & M.D. & T3NOMO \\
\hline Patient 1 & 98 & Male & Middle & W.D. & $\mathrm{T} 2 \mathrm{~N} 1 \mathrm{M} 0$ \\
\hline
\end{tabular}

"M.D." represents moderately differentiated and "W.D." represents well differentiated 
Table 2: Phenotypic characterization of immature and mature DCs by flow cytometry.

\begin{tabular}{lrr}
\hline & \% Immature DC & \% Mature DC \\
\hline CD14 & 0.9 & 4.7 \\
CD1a & 94.9 & 94.6 \\
CD80 & 11.49 & 39.29 \\
CD86 & 31.37 & 76.06 \\
CD83 & 10.84 & 58.94 \\
\hline
\end{tabular}

malignant transformation of cells by enhancing immune responses [12].

Dendritic cells have a unique capacity to capture, process, and present antigens that establish primary and secondary immune responses [13-15]. Taking advantage of their capabilities, DC transfection with nucleic acids encoding tumor specific antigens leads to processing and presenting the antigens and consequently, activating tumor-specific CTLs [6]. Considering this fact, DCs are proposed as an effective target for vaccinating cancer patients against tumor antigens and promoting an immune response against tumors [16,17]. It has been shown that RNA transfection of DCs offers numerous advantages over transferring other molecules $[18,19]$.
mRNA delivery system is an efficient method compared to the viral vectors as they do not pose the problems associated with viral vectors [20]. DCs can be introduced by total tumoral mRNA and the identification of tumor associated antigens (TAAs) or HLA-typing is not obligatory [21] especially in cancers such as ESCC in which wide variety of genotypic and phenotypic features lead to lack of specific tumor markers in different populations [20]. Loading total tumoral mRNA decreases the probability of immune escape via polyclonal activation of $\mathrm{T}$ cells against varied range of tumor-specific antigens and minimizes the consequences of antigen loss in mutant tumor cell clones. As RNA has a short half-life and lacks the ability to integrate into genome, many problems with viral vectors are not encountered [14]. With regards to gene expression, mRNA transfection is more efficient than DNA transfection as it bypasses the transcriptional regulation processes and has easy access to the cytoplasmic translation machinery when transferred into the cells [22]. Both CD4+ and CD8+ T lymphocytes will be activated by tumoral RNA transfer into DCs [23]. Electroporation has proved to be a more efficient method of gene transfer than many other techniques [22]. Thus, the electroporation method was utilized in order to achieve efficient total mRNA transfer into DCs as the preliminary step of a DC vaccine design for ESCC. In the present study, the results of mRNA transfer efficiency with elec-
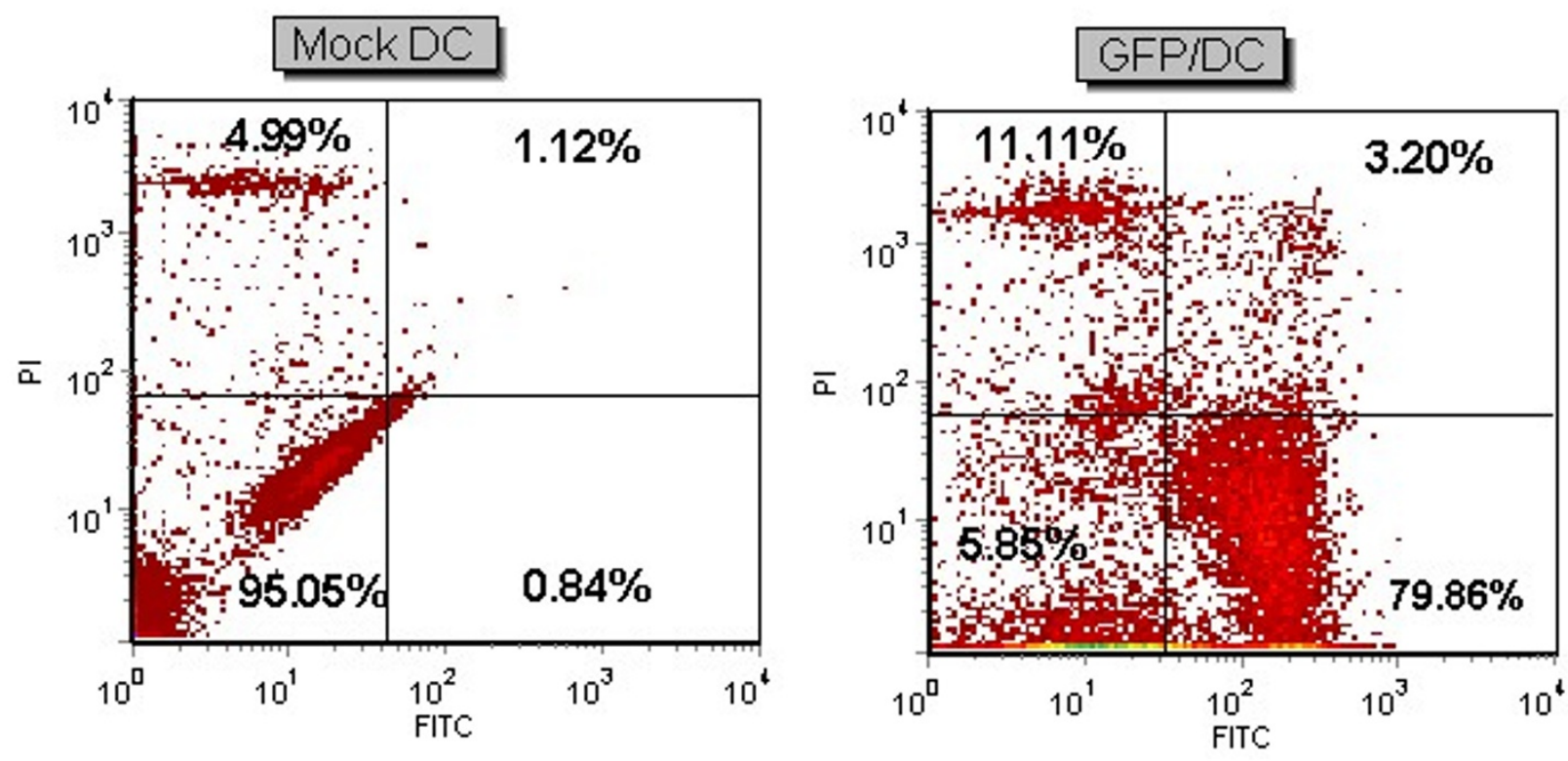

Figure 1 mRNA transfection of DC. GFP mRNA delivery into DCs of patient 1 with electroporation (500 V, $300 \mu s)$. FACS analysis of transfected DC and Mock as a control is shown. Viability percentage was $85.7 \%$ in transfected cells as compared with $93.9 \%$ in control Mock. Transfection efficiency was $79.8 \%$. 

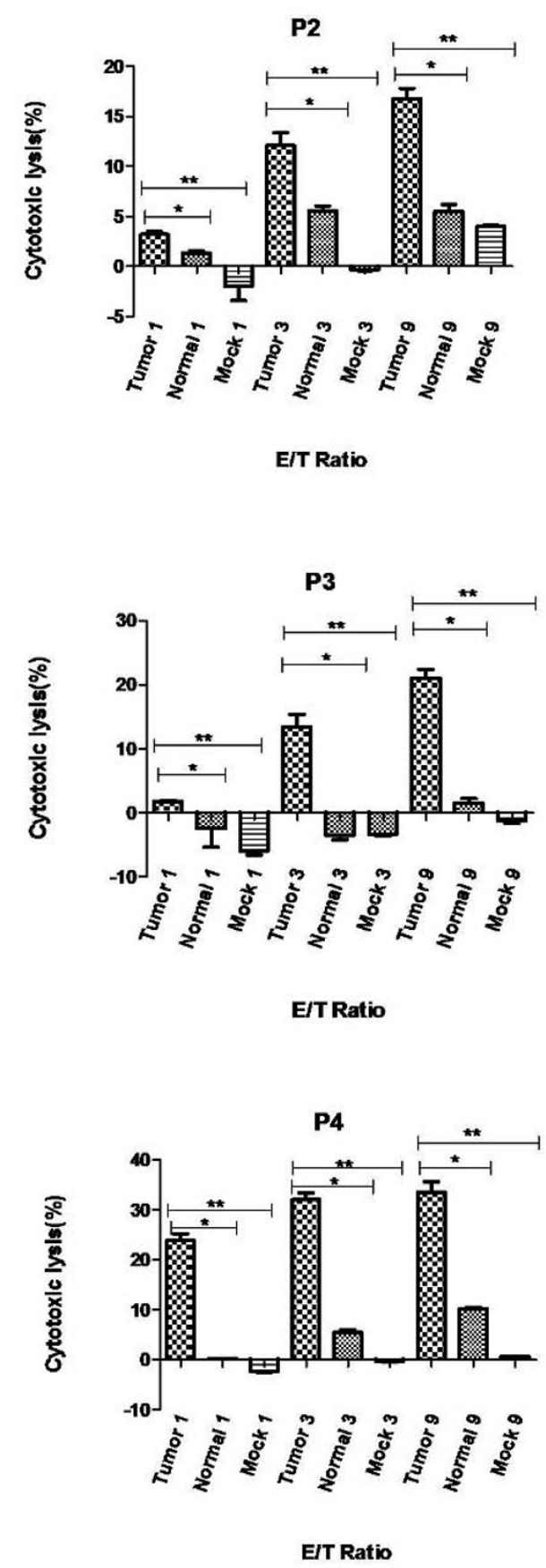

Figure 2 Cytotoxicity assay results representing cytotoxic activity of CTLs induced by DC/tumor-mRNA. Cytotoxicity assay was performed against DC/Tumor mRNA, DC/Normal mRNA and DC/Mock as targets at various effector:target (E:T) ratios assessed by Calcein-AM release assay. Experiments were repeated three times, and representative data of similar results are shown. For example, in the patient 3 cytotoxicity against DC/Tumor-mRNA, DC/Normal mRNA and DC/ Mock were $22 \%, 2 \%$ and $-1 \%$ respectively. ${ }^{*} p<0.05$ (Tumor vs. Normal); ** $\mathrm{p}<0.05$ (Tumor vs. Mock). troporation (approximately 80\%) were comparable to the previous reports of highly efficient transfer applying the same method [5,24].

Clinical trials using antigen-loaded DCs have been published in various types of cancer including myeloid leukemia [25], medullary thyroid carcinoma [26], metastatic melanoma [27], pancreas cancer [28], colorectal cancer [29] and other malignancies. To our knowledge, only Millano et al have reported DC therapy on two ESCC patients in addition to five esophageal adenocarcinomas with some technical variations compared to our study [30]. Our results show that primed T lymphocytes have obtained the capability to lyse the tumor RNA-loaded DCs. The percentage of lysis varies between 17.5 and 35 in the E:T ratio of 9. A serious limitation of this study was restricted amount of DCs since we were not able to perform leukophoresis in our patients. Many studies have performed the cytotoxicity assay in higher ratios [31,32]. However, due to our restrictions in the available amount of DCs, we did not perform the assay in higher ratios and probably in higher E:T ratios, greater percentage of cytotoxicity might have been observed. Cytotoxicity percentage in the mock DCs, as in controls, was negligible.

Transfecting DCs with total tumor RNA brings up a major concern of a consequent adverse effect through breaking tolerance towards self antigens and thus destructing effects on normal tissues as well. In the present study, cytotoxicity against normal RNA-loaded DCs was minor while lytic activity of primed $\mathrm{T}$ cells induced by DCs loaded with tumor RNA was significantly higher than normal RNA-loaded DCs in each patient and when comparing the average of both groups by paired $t$-test. Millano et al have reported enhanced lytic response against some of the studied normal tissues in esophageal adenocarcinoma suggesting the possibility of adverse effects against normal tissues in esophageal cancer [30]. Therefore, a preclinical ex vivo autologous assessment may be a wise step to include the beneficiary cases and predict the possibility of the adverse effects.

\section{Conclusion}

In summary, we demonstrated that electroporating DCs with tumor mRNA will enhance the cytotoxic effects of $\mathrm{T}$ cells against tumor in ESCC patients. Enhanced cytotoxicity induced by tumor RNA-loaded DCs is introduced as a useful autologous ex vivo screening tool for confirming the lytic effects of primed $\mathrm{T}$ cells on tumor and evaluates probable further adverse effects on noncancerous tissues. Enhancing cytotoxicity against tumoral cells is a crucial preliminary step to establish a total tumor RNA-pulsed DC vaccine therapy of ESCC. 


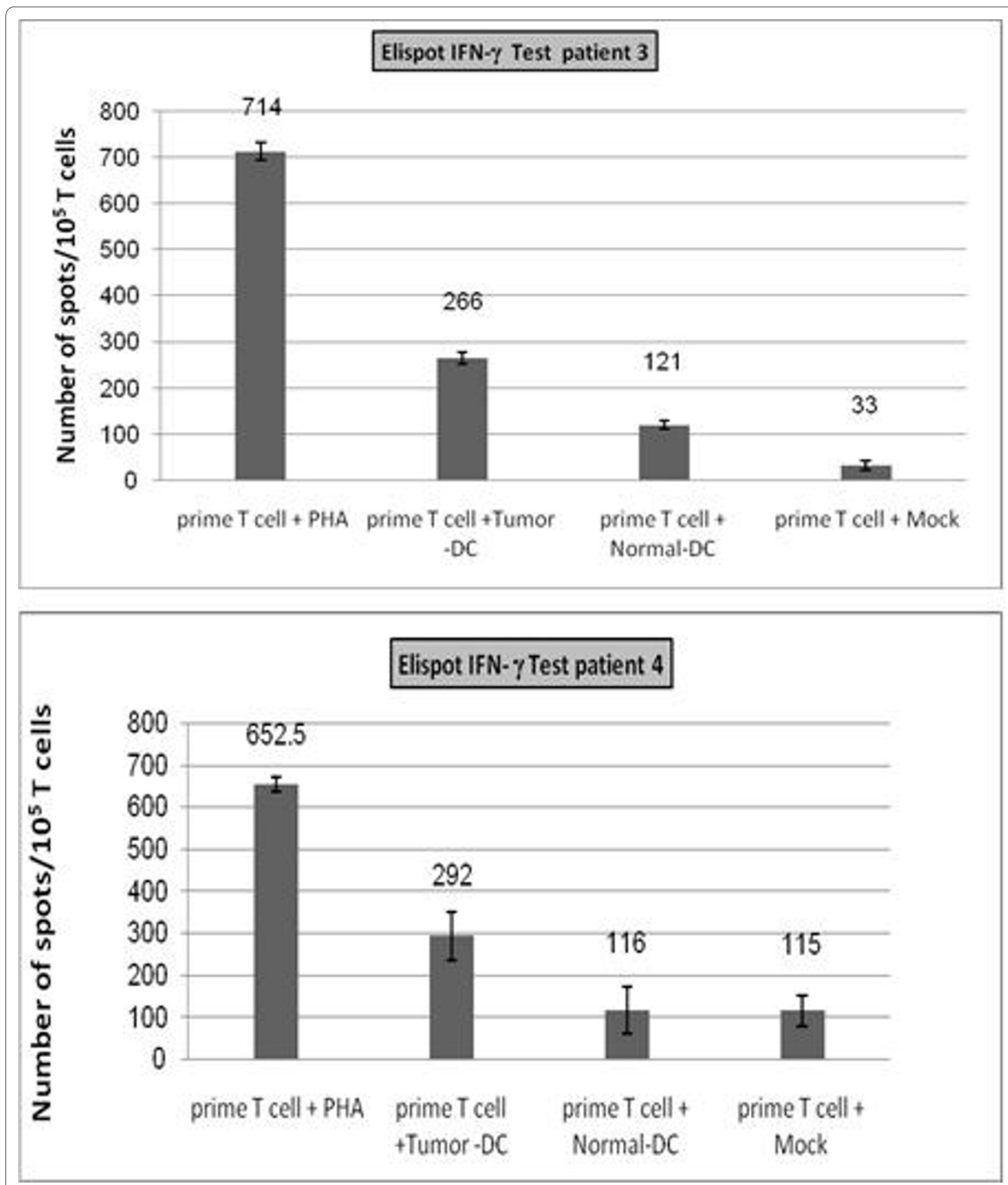

Figure 3 INF- $\gamma$ secretion Elispot assay results. INF- $\gamma$ spots are counted per $10^{5}$ T cells. Results are recorded as mean number of INF- $\gamma$ spots with $95 \%$ confidence interval (CI) indicated on the bars. Specific T cell activation and INF- $\gamma$ secretion was more than 2-folds higher in DC/Tumor-mRNA when compared to DC/Normal-mRNA in both patients $(p<0.05)$. 


\section{Competing interests}

The authors declare that they have no competing interests.

\section{Authors' contributions}

MG participated in the study design, carried out the experimental assays, analyzed the data and participated in drafting the manuscript. OM drafted the manuscript, participated in patient collection and carried out statistical analysis and data interpretation. MF participated in the experimental assays and data analysis. MM and MS participated in the study design, coordination and data interpretation. BM carried out data collection and tissue preparation. RM, MTRM and MNF participated in sample and data collection and study coordination. MRA participated in study design and coordination, data interpretation and scientific revision of the manuscript. All authors read and approved the final manuscript

\section{Acknowledgements}

We are very grateful to Dr. Eli Gilboa for generously providing us with the EGFP plasmid and his valuable consults. This study was supported by grants from Mashhad University of Medical Sciences, Iran National Science Foundation and Digestive Disease Research Center of Tehran University of Medical Sciences. The results described in this paper were part of a Ph.D. student dissertation.

\section{Author Details}

'Division of Human Genetics, Immunology Research Center, Avicenna Research Institute, Mashhad University of Medical Sciences (MUMS), Mashhad, Iran, 2Department of Molecular Immunology, Immunology Research Center, MUMS, Mashhad, Iran, ${ }^{3}$ Department of Immunobiochemistry, Immunology Research Center, MUMS, Mashhad, Iran, ${ }^{4}$ Department of Pathology, Omid Hospital, MUMS, Mashhad, Iran, 5Digestive Disease Research Center, Tehran University of Medical Sciences, Tehran, Iran and ${ }^{6}$ Department of Surgery, Omid Hospital, MUMS, Mashhad, Iran

Received: 16 November 2009 Accepted: 7 June 2010 Published: 7 June 2010

\section{References}

1. Mousavi SM, Gouya MM, Ramazani R, Davanlou M, Hajsadeghi N, Seddighi Z: Cancer incidence and mortality in Iran. Ann Oncol 2009, 20(3):556-563.

2. Kamangar F, Malekzadeh R, Dawsey SM, Saidi F: Esophageal cancer in Northeastern Iran: a review. Arch Iran Med 2007, 10(1):70-82.

3. Burnet FM: The concept of immunological surveillance. Prog Exp Tumor Res 1970, 13:1-27.

4. Rajjoub S, Basha SR, Einhorn E, Cohen MC, Marvel DM, Sewell DA: Prognostic significance of tumor-infiltrating lymphocytes in oropharyngeal cancer. Ear Nose Throat J 2007, 86(8):506-511.

5. Landi A, Babiuk LA, van Drunen Littel-van den Hurk S: High transfection efficiency, gene expression, and viability of monocyte-derived human dendritic cells after nonviral gene transfer. J Leukoc Biol 2007, 82(4):849-860.

6. Brossart $\mathrm{P}, \mathrm{Wirths} \mathrm{S}$, Brugger $\mathrm{W}, \mathrm{Kanz} \mathrm{L}$ : Dendritic cells in cancer vaccines. Exp Hematol 2001, 29(11):1247-1255

7. Banchereau J, Palucka AK: Dendritic cells as therapeutic vaccines against cancer. Nat Rev Immunol 2005, 5(4):296-306.

8. Van Bockstaele F, Pede V, Naessens E, Van Coppernolle S, Van Tendeloo V, Verhasselt B, Philippe J: Efficient gene transfer in CLL by mRNA electroporation. Leukemia 2008, 22(2):323-329.

9. Mu LJ, Gaudernack G, Saeboe-Larssen S, Hammerstad H, Tierens A, Kvalheim G: A protocol for generation of clinical grade mRNAtransfected monocyte-derived dendritic cells for cancer vaccines. Scand J Immuno/ 2003, 58(5):578-586.

10. Boczkowski D, Nair SK, Snyder D, Gilboa E: Dendritic cells pulsed with RNA are potent antigen-presenting cells in vitro and in vivo. J Exp Med 1996, 184(2):465-472.

11. Minami $K$, Yamaguchi $Y$, Ohshita A, Kawabuchi Y, Ohta K, Hihara J, Toge T: Generation of antigen-presenting cells using cultured dendritic cells and amplified autologous tumor mRNA. Oncology 2005, 69(5):399-407.

12. Gholamin M, Moaven O, Memar B, Farshchian M, Naseh H, Malekzadeh R, Sotoudeh M, Rajabi-Mashhadi MT, Forghani MN, Farrokhi F, Abbaszadegan MR: Overexpression and interactions of interleukin-10, transforming growth factor beta, and vascular endothelial growth factor in esophageal squamous cell carcinoma. World J Surg 2009, 33(7):1439-1445.

13. Banchereau J, Schuler-Thurner B, Palucka AK, Schuler G: Dendritic cells as vectors for therapy. Cell 2001, 106(3):271-274

14. Van Tendeloo VF, Ponsaerts P, Berneman ZN: mRNA-based gene transfer as a tool for gene and cell therapy. Curr Opin Mol Ther 2007, 9(5):423-431.

15. Kyte JA, Gaudernack G: Immuno-gene therapy of cancer with tumourmRNA transfected dendritic cells. Cancer Immunol Immunother 2006 , 55(11):1432-1442.

16. Salcedo M, Bercovici N, Taylor R, Vereecken P, Massicard S, Duriau D, Vernel-Pauillac F, Boyer A, Baron-Bodo V, Mallard E, et al.: Vaccination of melanoma patients using dendritic cells loaded with an allogeneic tumor cell lysate. Cancer Immunol Immunother 2006, 55(7):819-829.

17. Hersey P, Halliday GM, Farrelly ML, DeSilva C, Lett M, Menzies SW: Phase I/ II study of treatment with matured dendritic cells with or without low dose IL-2 in patients with disseminated melanoma. Cancer Immunol Immunother 2008, 57(7):1039-1051.

18. Boczkowski D, Nair SK, Nam JH, Lyerly HK, Gilboa E: Induction of tumor immunity and cytotoxic T lymphocyte responses using dendritic cells transfected with messenger RNA amplified from tumor cells. Cancer Res 2000, 60(4):1028-1034.

19. Nair SK, Boczkowski D, Morse M, Cumming RI, Lyerly HK, Gilboa E: Induction of primary carcinoembryonic antigen (CEA)-specific cytotoxic T lymphocytes in vitro using human dendritic cells transfected with RNA. Nat Biotechnol 1998, 16(4):364-369.

20. Dietz AB, Vuk-Pavlovic S: High efficiency adenovirus-mediated gene transfer to human dendritic cells. Blood 1998, 91(2):392-398.

21. Ohshita A, Yamaguchi Y, Minami K, Okita R, Toge T: Generation of tumorreactive effector lymphocytes using tumor RNA-introduced dendritic cells in gastric cancer patients. Int J Oncol 2006, 28(5):1163-1171.

22. Saeboe-Larssen S, Fossberg E, Gaudernack G: mRNA-based electrotransfection of human dendritic cells and induction of cytotoxic T lymphocyte responses against the telomerase catalytic subunit (hTERT). J Immunol Methods 2002, 259(1-2):191-203.

23. Ponsaerts $P$, Van Tendeloo VF, Berneman ZN: Cancer immunotherapy using RNA-loaded dendritic cells. Clin Exp Immunol 2003, 134(3):378-384

24. Van Tendeloo VF, Ponsaerts P, Lardon F, Nijs G, Lenjou M, Van Broeckhoven C, Van Bockstaele DR, Berneman ZN: Highly efficient gene delivery by mRNA electroporation in human hematopoietic cells: superiority to lipofection and passive pulsing of mRNA and to electroporation of plasmid CDNA for tumor antigen loading of dendritic cells. Blood 2001, 98(1):49-56.

25. Van Driessche A, Van de Velde AL, Nijs G, Braeckman T, Stein B, De Vries $J M$, Berneman ZN, Van Tendeloo VF: Clinical-grade manufacturing of autologous mature mRNA-electroporated dendritic cells and safety testing in acute myeloid leukemia patients in a phase I dose-escalation clinical trial. Cytotherapy 2009:1-16.

26. Bachleitner-Hofmann T, Friedl J, Hassler M, Hayden H, Dubsky P, Sachet M, Rieder E, Pfragner R, Brostjan C, Riss S, et al:: Pilot trial of autologous dendritic cells loaded with tumor lysate(s) from allogeneic tumor cell lines in patients with metastatic medullary thyroid carcinoma. Oncol Rep 2009, 21(6):1585-1592.

27. Kyte JA, Mu L, Aamdal S, Kvalheim G, Dueland S, Hauser M, Gullestad HP, Ryder T, Lislerud K, Hammerstad $\mathrm{H}$, et al:: Phase I/II trial of melanoma therapy with dendritic cells transfected with autologous tumor-mRNA. Cancer Gene Ther 2006, 13(10):905-918.

28. Kalady MF, Onaitis MW, Emani S, Abdul-Wahab Z, Pruitt SK, Tyler DS Dendritic cells pulsed with pancreatic cancer total tumor RNA generate specific antipancreatic cancer T cells. J Gastrointest Surg 2004, 8(2):175-181.

29. Burgdorf SK, Fischer A, Myschetzky PS, Munksgaard SB, Zocca MB, Claesson MH, Rosenberg J: Clinical responses in patients with advanced colorectal cancer to a dendritic cell based vaccine. Oncol Rep 2008, 20(6):1305-1311.

30. Milano F, Rygiel AM, Buttar N, Bergman JJ, Sondermeijer C, van Baal JW, ten Brinke A, Kapsenberg M, van Ham SM, Peppelenbosch MP, et al: An ex vivo readout for evaluation of dendritic cell-induced autologous 
cytotoxic T lymphocyte responses against esophageal cancer. Cancer Immunol Immunother 2007, 56(12):1967-1977.

31. Heiser A, Maurice MA, Yancey DR, Wu NZ, Dahm P, Pruitt SK, Boczkowski D, Nair SK, Ballo MS, Gilboa E, et al:: Induction of polyclonal prostate cancerspecific CTL using dendritic cells transfected with amplified tumor RNA. J Immunol 2001, 166(5):2953-2960.

32. Heiser A, Maurice MA, Yancey DR, Coleman DM, Dahm P, Vieweg J: Human dendritic cells transfected with renal tumor RNA stimulate polyclonal T-cell responses against antigens expressed by primary and metastatic tumors. Cancer Res 2001, 61(8):3388-3393.

\section{Pre-publication history}

The pre-publication history for this paper can be accessed here: http://www.biomedcentral.com/1471-2407/10/261/prepub

doi: 10.1186/1471-2407-10-261

Cite this article as: Gholamin et al., Induction of cytotoxic T lymphocytes primed with Tumor RNA-loaded Dendritic Cells in esophageal squamous cell carcinoma: preliminary step for DC vaccine design BMC Cancer 2010, 10:261

Submit your next manuscript to BioMed Central and take full advantage of:

- Convenient online submission

- Thorough peer review

- No space constraints or color figure charges

- Immediate publication on acceptance

- Inclusion in PubMed, CAS, Scopus and Google Scholar

- Research which is freely available for redistribution

Submit your manuscript at www.biomedcentral.com/submit
C) Biomed Central 